\title{
Emotion Regulation and Pre-Performance Routines in Competitive Sports
}

\author{
Sabrina K. Sobhy ${ }^{1}$, Andrew C Muran ${ }^{2}$ and J. Christopher Muran ${ }^{3 *}$ \\ ${ }^{1}$ Harvard University, USA \\ ${ }^{2}$ Cornell University, USA
}

${ }^{3}$ Adelphi University, Mount Sinai School of Medicine, USA

Authors' note: The first two authors contributed equally to this article.

*Corresponding author: JC Muran, Ph.D, Gordon F Derner School of Psychology, Adelphi University, 158 Cambridge Avenue, Hy Weinberg Center, Garden City, New York, NY 11530, USA

Submission: 眥 June 18, 2018; Published: 㘹 July 13, 2018

\begin{abstract}
This article attempts to integrate the literature on emotion regulation (i.e., the trajectory of emotional experience) and on pre-performance routines (i.e., how performers prepare themselves in advance to maximize their performance). The authors propose that the development of preperformance routines can be advanced by careful consideration of contemporary research on emotion regulation. Recent research on the neural effects of music on regulating emotion is highlighted.
\end{abstract}

Keywords: Emotion regulation; Pre-performance routines

\section{Emotion Regulation and Pre-Performance Routines in Competitive Sports}

Under pressure, when one perceives much is at stake and dependent on one's performance, it is a challenge to manage one's emotions. This is especially true in competitive sports where an important part of being a successful athlete involves developing strategies to regulate one's own emotions [1]. Sports performance today has become increasingly more focused on the psychological aspects of the sport rather than just the physicality of the athlete. Athletes and coaches have recently acknowledged the importance of a pre-performance routine to reach peak performance. In this paper, we will review the literature on emotion regulation and then consider pre-performance routines (PPRs) as an emotion regulation strategy. We will introduce basic definitions and provide supporting research. We will conclude by suggesting future directions on research regarding PPRs.

\section{Emotion Regulation}

Emotion regulation refers to mental and behavioral processes by which we shape and change the trajectory of our emotions. Gross [2] defined emotion regulation as "the processes by which individuals influence the emotions they have, when they have them, and how they experience and express these emotions" (p. 275). He outlined the essential strategies of emotion regulation as follows: (1) situation modification, which involves avoiding or altering situations that typically stimulate to an emotion; (2) attentional deployment, which most commonly involves distraction or redirection away from a situation or aspects of it; (3) cognitive reappraisal or change, which involves altering or reframing how one interprets and thus experiences a situation; (4) response modulation or suppression, which involves any exercise or technique to inhibit an emotion.

Research on emotion regulation has largely been focused on the neural mechanisms involved in emotion regulation and comparisons of the different regulation strategies. The research regarding the neural mechanisms in emotion regulation supports the idea of "top down regulation," which involves control of the limbic system (regarded as the system responsible for emotion generation) by the prefrontal cortex, a region implicated in cognitive control $[3,4]$. Research has shown that cognitive reappraisal increases activity in the prefrontal and cingulate regions (cognitive control centers) and decreases activity in the structures of the limbic system such as the amygdala, insula and striatum (the emotion generation centers [57]).

Research comparing the different strategies has found reappraisal, distraction and suppression to all be effective. However, reappraisal was shown to be significantly more effective at increasing and decreasing neural activity in the prefrontal cortex and limbic system respectively [8,9]. Gross et al. [9] also found that the use of regulation strategies varied among individuals, but that the greater the use of reappraisal, the better the mental health of 
the individual. Other studies comparing reappraisal and another strategy termed acceptance (a strategy like mindfulness) found that acceptance was more effective than appraisal, resulting in less subjective distress and amygdala activity when a subject was presented with a negative memory as a stimulus [9]. In addition, a strategy called affect labeling (what Barrett [10] described as granularity) was found to be more effective in reducing skin conductance and amygdala activity when compared with reappraisal and distraction [11,12]. Finally, there is a growing body of research demonstrating the regulatory effect of music on emotion $[13,14]$.

\section{Pre-Performance Routines}

Pre-performance routines (PPRs) have long existed as part of an athlete's regimen intended to improve performance $[15,16]$. The literature makes a distinction between pre-shot routines implemented for closed skills (such as a golf shot, basketball free throw, soccer penalty kick) and pre-competitive routines used for open skills (such as a match, game, or event). These routines are constantly adjusted as athletes and coaches try to find an individualized balance of psychological and physical methods that maximizes performance. PPRs vary in their structure and content with methods to meet the athlete's individualized needs but generally include an "ordered collection of thoughts and behaviors" [17] designed to "intentionally help regulate arousal and concentration" [18]. Moran [19] provided a definition of PPR as "a sequence of task-relevant thoughts and actions which an athlete engages in systematically prior to his or her performance of a specific sports skill” (p. 177).

As athletes and coaches increasingly appreciate the benefits of pre-performance routines, research has provided support for its effect: Specifically, PPRs have been shown to help performers better focus their thoughts on task-relevant cues, overcome natural instincts to dwell on negatives thoughts, reduce the impact of distractions during performance, and increase attention to the devotion to mechanics of automatic skills [15]. Researchers have also tried to identify the essential characteristics to include in a PPR. Cotterill [15], for example, proposed that all successful PPRs involve an integration of temporal and behavioral elements with the athlete's psychological processes. Singer's [20] five-step approach to performing, including readying, imaging, and focusing (as well as executing and evaluating), has proved beneficial for many athletes. Lidor \& Tenenbaum [21] found the most important stage to be the readying stage; they reported that the greater preparation time, the greater the success rate. There is also some, though not a great deal of research examining the impact of music on the readying stage of PPRs [22-24].

\section{Conclusions \& Future Directions}

Parallel to the spike in research on emotion regulation over the past 25 years, there has been increasing attention to the development and study of PPRs. It appears, however, there is much that can be gained by integrating these literatures. Specifically, PPRs could be significantly augmented by considering the application of reappraisal, acceptance-based, and affect-labeling strategies from the emotion regulation literature. Moreover, research on the impact of music on emotion regulation can advance our understanding of how PPRs can be tailored for greater effect. As some research suggests [25,26], music has a complicated impact on neural activity that appears to go beyond emotion regulation: There is more to understand in this regard. In short, the better we understand the neuroscience of emotion regulation, the better we can refine PPRs to maximize performance, including performance under pressure.

\section{References}

1. Beilock S (2010) Choke: What the secrets of the brain reveal about getting it right when you have to. Simon and Schuster, New York, USA.

2. Gross JJ (1998) The emerging field of emotion regulation: An integrative review. Review of General Psychology 2(3): 271-299.

3. Johnston E, Olson L (2015) The feeling brain: The biology and psychology of emotions. Norton, New York, USA.

4. Lieberman MD (2009) The brain's braking system (and how to "use your words" to tap into it). Neuroleadership 2: 9-14.

5. Ochsner KN, Bunge SA, Gross JJ, Gabrieli JD (2002) Rethinking feelings: An FMRI study of the cognitive regulation of emotion. J Cogn Neurosci 14(8): 1215-1229.

6. Ochsner KN, Silvers JA, Buhle JT (2012) Functional imaging studies of emotion regulation: A synthetic review and evolving model of the cognitive control of emotion. Ann N Y Acad Sci 1251: E1-E24.

7. McCrae K, Ochsner KN, Mauss IB, Gabrieli JJ, Gross JJ (2008) Gender differences in emotion regulation: An fMRI study of cognitive reappraisal. Group Processes \& Intergroup Relations 11(2): 143-162.

8. Goldin PR, McRae K, Ramel W, Gross JJ (2008) The neural bases of emotion regulation: Reappraisal and suppression of negative emotion. Biol Psychiatry 63(6): 577-586.

9. Gross JJ, John OP (2003) Individual differences in two emotion regulation processes: Implications for affect, relationships, and well-being. J Pers Soc Psychol 85(2): 348-362.

10. Barrett LF (2018) How emotions are made. Pan Books, New York, USA.

11. Lieberman MD, Eisenberger NI, Crockett MJ, Tom SM, Pfeifer JH, et al. (2007) Putting feelings into words: Affect labeling disrupts amygdala activity in response to affective stimuli. Psychol Sci 18(5): 421-428.

12. Kircanski K, Lieberman MD, Craske MG (2012) Feelings into words: contributions of language to exposure therapy. Psychol Sci 23(10): 1086-1091.

13. Moore KS (2013) A systematic review on the neural effects of music on emotion regulation: implications for music therapy practice. J Music Ther 50(3): 198-242.

14. Saarikallio S (2016) Music as emotion regulation. Musicae Scientiae 20(1): 10.

15. Cotterill S (2010) Pre-performance routines in sport: Current understanding and future directions. Int Rev Sport Exer Psych 3(2): 132-153.

16. Mesagno C, Mullane-Grant T (2010) A comparison of different preperformance routines as possible choking interventions. Journal of Applied Sport Psychology 22(3): 343-360.

17. Crampton J (1989) Establishing pre-shot routines for tournament golfers: An example of the use of micro-computers in performance planning. Sports Coach 12: 9-12.

18. Foster DJ, Weigand DA, Baines D (2006) The effect of removing superstitious behavior and introducing pre-performance routine on basketball free-throw performance. J Appl Sport Psycho 18(2): 167-171. 
19. Moran AP (1996) The psychology of concentration in sports performers: A cognitive analysis. Psychology Press, New York, USA.

20. Singer RN (2002) Pre-performance state, routines, and automaticity: what does it take to realize expertise in self-paced events? Journal of Sport \& Exercise Psychology 24: 359-375.

21. Lidor R, Tenenbaum G (1993) Applying learning strategy to a basketball shooting skill: A case study report, Bitnu'a 108-126.

22. Pain MA, Harwood C, Anderson R (2011) Pre-competition imagery and music: The impact on flow and performance in competitive soccer. The Sport Psychologist 25(2): 212-232.

23. Kross E, Davidson M, Weber J, Ochsner K (2009) Coping with emotions past: The neural bases of regulating affect associated with negative autobiographical memories. Biol Psychiatry 65(5): 361-366.
24. Shaw D (2002) Confidence and pre-shot routine in golf: A case study. In Cockerill I (Ed.), Solutions in Sports Psychology Thomson, London, UK, pp.108-119.

25. Salimpoor VN, Benovoy M, Larchner K, Dagher A, Zatorre RJ (2011) Anatomically distinct dopamine release during anticipation and experience of peak emotion to music. Nat Neurosci 14: 257-262.

26. Salimpoor VN, van den Bosch I, Kovacevic N, McIntosh AR, Dagher A (2013) Interactions between the nucleus accumbens and auditory cortices predict music reward value. Science 340(6129): 216-219.
Creative Commons Attribution 4.0

International License

For possible submissions Click Here

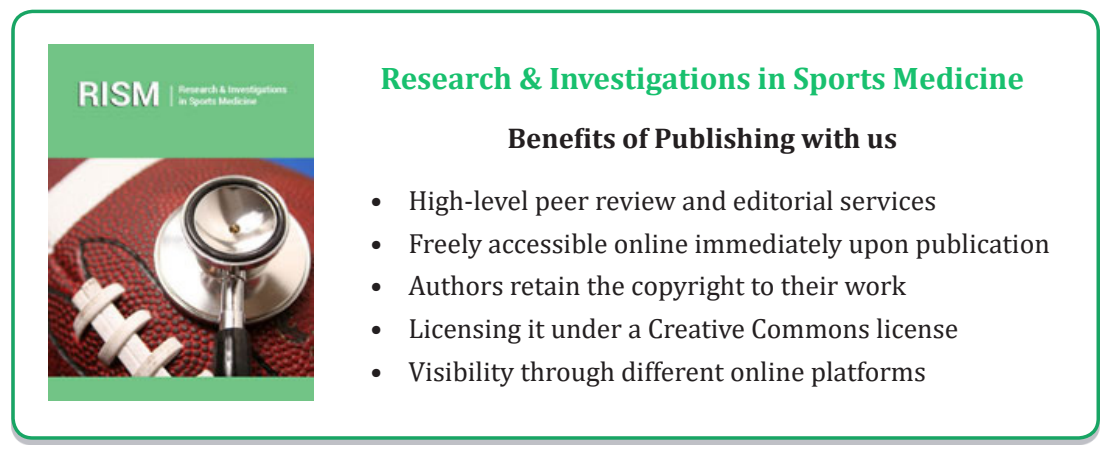

